\title{
Electrochemical Detection of Pesticide in Living Plant and Fish Brain Cell
}

\author{
Chang-Hyun Lee*, Suw-Young Ly ${ }^{1)}$ \\ Division of General Education, Pyeongtaek University, Gyeonggi 405-701, Korea \\ ${ }^{1)}$ Biosensor Research Institute,Seoul National University of Technology, Seoul 139-743, Korea \\ (Manuscript received 3 May, 2010; revised 17 June, 2010; accepted 13 July, 2010)
}

\begin{abstract}
The three electrode system was used to detect the pesticide fenitrothion $\left(\mathrm{C}_{9} \mathrm{H}_{12} \mathrm{NO}_{5} \mathrm{PS}\right.$. MW=277.24) using cyclic voltammetry (CV) and square wave anodic stripping voltammetry (SWASV). The working electrode was mercury immobilized on a carbon nanotube paste electrode (Hg-CNTPE). At the optimized condition, the limit of detection (LoD) was $0.6 \mathrm{ppt}\left(2.16 \times 10^{-12} \mathrm{M}\right)$, and the relative standard deviation was $0.035 \%(\mathrm{n}=15)$. And there is more sensitive in detecting fenitrothion than common type carbon nanotube paste electrode. When it was implanted into the brain of live fish (carp), the existence of fenitrothion was measured without any destruction or damage of tissue.
\end{abstract}

Key Words : Fenitrothion, Hg, Nanotube, Stripping, Voltammetry, Fish, Brain

\section{Introduction}

Fenitrothion, among 430 different pesticides used in Korea, is very effective for insects and relatively less dangerous for mammal like human being and farm animals, so that it is being broadly used by farmers. However, it was the pesticide that killed sweet fishes in Kangjeongchun in Jeju on June 22, 2009 , and has destroyed the ecosystem of rivers in form of residue in agricultural products. Fenitrothion pesticide easily remains in beverages such as wine and fruit juice (Zambonion et al., 2004) grains such as wheat, fruits such as strawberries and cherries (Lambropoulou et al., 2003), in the forests (Baroja et al., 2004) and on the soil(Sanlnchez et al., 2004).

*Corresponding author : Chang-Hyun Lee, Division of General Education, Pyeongtaek University, Gyeonggi 405-701, Korea Phone: +82-31-659-8384

E-mail: lch@ptu.ac.kr
This pesticide is used widely in agriculture (Sudo et al., 2002)to protect crops from insects. Thus it can affect human beings and it can be detected in human urine and tissue (Hernandez et al., 2004). The rising incidence of brain, prostate and other types of cancer is attributed to pesticide contamination (Khuder et al., 1998; Settimi et al., 2003). For this reason, detection of fenitrothion is very important, and methods of detecting this substance have been developed in the past. Previous methods include headspace-solid phase microextraction (HS-SPME) (Tsoukali et al., 2005), gas chromatography (GC) (Sanchez-Ortega et al., 2005), high-resolution gas chromatography and flame photometric detection (HRGC-ECD/FPD) (Zuin et al., 2003), membrane- assisted solvent extraction combined with gas chromatography-mass spectrometry (Schellin et al., 2004), liquid chromatography combined with tandem mass spectrometry (LC-LC-MS/MS) 
(Hernandez et al., 2004) and high performance liquid chromatography (HPLC) (Bhushan et al., 2000). All these methods are effective enough to detect fenitrothion, but they are relatively complicated to use and require compressing or separation systems. To find more simple and sensitive methods, many researchers started to use electrochemical methods (Solna et al., 2005) to trace organophosphorus pesticides. For example, a micro flow injection electrochemical biosensor (Neufeld et al., 2000), a disposable cholinesterase biosensor based on screen-printed electrode (Montesions et al., 2001), and amperometric microbial biosensor achieved detection limits of $1 \mathrm{uM}$ for methyl parathion and 200 nM for paraoxon (Mulchandani et al., 2001); potentiometric biosensors based on butyrylcholinesterase electrode showed a detection limit for trichlorfon below $10^{-7} \mathrm{M}$ (Raybier et al., 2002); a dual amperometric/potentiometric FIA-based biosensor was observed with a detection limit of $0.1 \mathrm{uM}$ for the pesticide (paraoxon) (Schoning et al., 2003); an acetylcholinesterase biosensor using a nanoporous carbon matrix showed a detection limit of $10^{-12} \mathrm{M}$ dichlorvos (Sotiropoulou et al., 2005); a mediatorfree screen-printed amperometric biosensor achieved a detection limit of $10 \mathrm{nM}$ dichlorvos (Shi et al., 2006); amperometric enzymatic biosensors based on the immobilized tyrosinase enzyme obtained a detection limit of $0.06 \mathrm{uM}$ dichlorvos (Vidal et al., 2006) and HMDE achieved a low detection limit of $4.5 \mathrm{ugL}^{-1}$ pesticide (Ni et al., 2006). However, articles about fenitrothion are few. In this study, mercury immobilized on carbon nanotube electrode was used as a working electrode to enhance detecting ability of fenitrothion. and investigated optimum parameters.

\section{Experiment}

2.1. Apparatus, reagents and experimental procedure

Cyclic voltammetry (CV) and square wave anodic stripping voltammetry (SWASV) were used to monitor fenitrothion using the $\mathrm{CHI}-660 \mathrm{~A}$ instruments electrochemical workstation (CH Instruments INC., Cordova TN, USA). $\mathrm{Ag} / \mathrm{AgCl}$ reference electrode, platinum counter electrode and Hg-CNTPE working electrode were utilized as three-electrode systems. Moreover, $\mathrm{Ag} / \mathrm{AgCl}$ wire type reference electrode was made using chloride coated silver wire. It was used on the implanted cell systems, with wire-type platinum electrode. Hg-CNTPE was completed by mixing $\mathrm{Hg}$ (1000 ppm standard solution), carbon nanotube powder (Nanotech Co., LTD., Choongnam, South Korea) and mineral oil based on a 40:40:20 ratios. These were mixed for five minutes and $0.1 \mathrm{~g}$ of the mixture was inserted into a needle-type-capillary tube (Scientific Glass, Inc., Rockwood, USA), whose diameter was $0.2 \mathrm{~mm} \pm 0.02 \mathrm{~mm}$ and length was 7 mm. 1000-ppm fenitrothion solution was prepared by melting $0.1 \mathrm{~g}$ fenitrothion powder (Labor Dr. Ehrenstorfer-Schafers, Germany) with $100 \mathrm{~mL}$

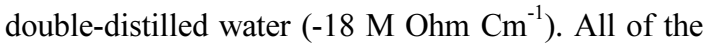
reagents used were standard grade. The electrolyte solution was $0.1 \mathrm{M}$ ammonium phosphate solution with $\mathrm{pH}$ of 4.6 to 4.8 .

\section{Results and Discussion}

\subsection{Electrode comparison using CV}

Fig. 1(a) demonstrates the concentration effect of common type carbon nanotube electrode between 10 $\sim 30 \mathrm{mgL}^{-1}$ fenitrothion spiked in $0.1 \mathrm{M}$ ammonium phosphate electrolyte solution. At this level, there was considerable noise without clear and manifest 


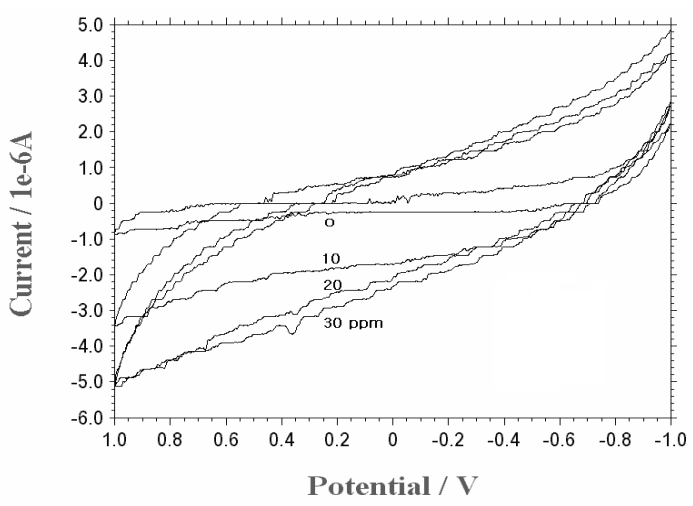

(a)

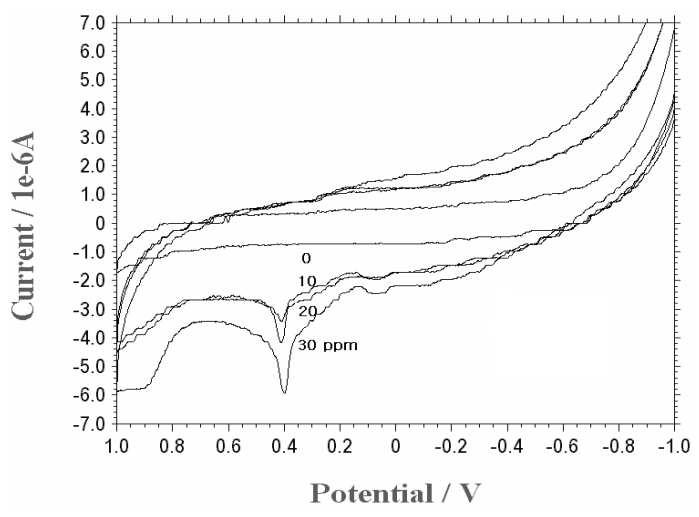

(b)

Fig. 1. (a) Cyclic voltammograms at common bare-type carbon nanotube paste electrode with various concentration of 10, 20 and $30 \mathrm{ppm}$ fenitrothion, scan rate of $5.5 \mathrm{Vs}^{-1}$ and (b) $\mathrm{CV}$ voltammograms at $\mathrm{Hg}$-CNTPE with diverse fenitrothion concentration of $10,20,30 \mathrm{ppm}$ with scan rate of $5.5 \mathrm{Vs}^{-1}$ under the same conditions.

peak current at oxidation and reduction scan. The $\mathrm{CV}$ peak current varied into $0,0.438$ and $0.224 \times 10^{-6} \mathrm{~A}$ at oxidation with a scan rate of $5.5 \mathrm{Vs}^{-1}$. At that time, the intervals between each signal were not linear and did not increase orderly. Nevertheless, the signals from Hg-CNTPE were more obvious and distinct. The result of this detection is shown in Fig. 1(b). The intervals between each oxidation signal presented relatively regular patterns unlike the result from common bare-type nanotube electrode. At that time, the voltammograms were expanded into 1.944, 2.538 and $2.865 \times 10^{-6} \mathrm{~A}$ and raised gradually, so that their increment could form a straight line. Also, definite and manifest peak current appeared at potential of 0.4 $\mathrm{V}$ at oxidation. Based on the CV result, $\mathrm{Hg}$-CNPTE is more sensitive than common bare type carbon nanotube paste electrode, and $\mathrm{Hg}$-CNTPE peak current was tenfold higher then bare type electrodes. Thus, more sensitive methods for SW stripping voltammetry were examined.

\subsection{Experimental optimization for various parameters} of square-wave stripping voltammogram

Fig. 2(a) shows SW signals from different amplitudes at the range of $0.10 \sim 0.40 \mathrm{~V}$ with $0.1 \mathrm{M}$ ammonium phosphate electrolyte solution in $50 \mathrm{ppm}$ fenitrothion spike. Given these parameters, the highest current was $0.20 \mathrm{~V}$, while the third current had $3.604 \times 10^{-6} \mathrm{~A}$. However, it could not be the optimum amplitude when the current position was investigated. The peak current of amplitude of $0.20 \mathrm{~V}$ appeared at the slight right side of $0.4 \mathrm{~V}$. Out of peaks that presented at 0.4 $\mathrm{V}, 0.15 \mathrm{~V}$ had the most powerful measurement of $3.522 \times 10^{-6} \mathrm{~A}$. As a result, $0.15 \mathrm{~V}$ was determined as the optimal amplitude. The parameters were optimum $\mathrm{pH}$ of 4.68 , initial potential of $-0.9 \mathrm{~V}$, final potential of $1.1 \mathrm{~V}$, increment of $0.015 \mathrm{~V}$ and frequency of 200 $\mathrm{Hz}$ and sensitivity of $1 \mathrm{e}^{-4} \mathrm{AV}^{-1}$. The optimum $\mathrm{pH}$ was already determined prior to this detection. In this condition, the optimum increment potential was also investigated at this detection with ammonium phosphate electrolyte solution of $0.1 \mathrm{M}$ and fenitrothion solution of 50 ppm. As Fig. 2(b) shows, all of the peak current from various increments presented at $0.4 \mathrm{~V}$. These currents had measurements between $3.934 \times 10^{-6} \mathrm{~A}$ and $7.673 \times 10^{-6} \mathrm{~A}$. The higher 


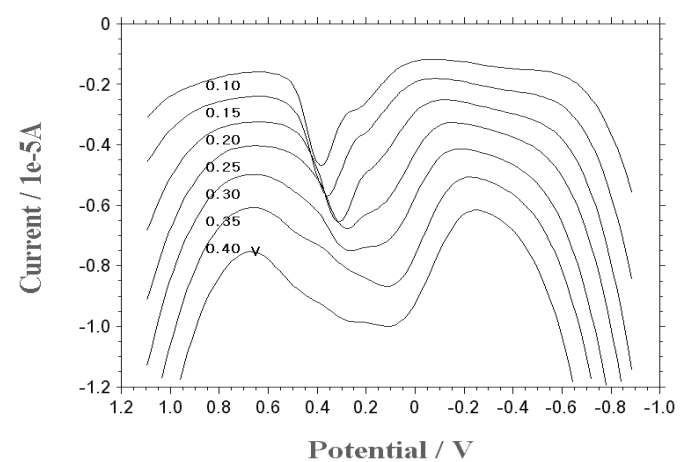

(a)

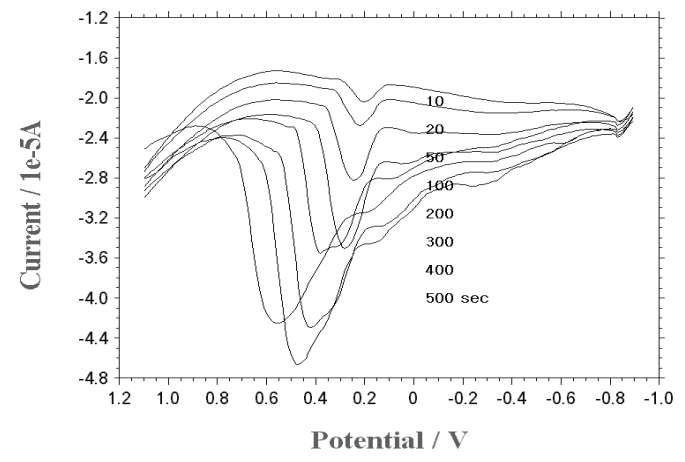

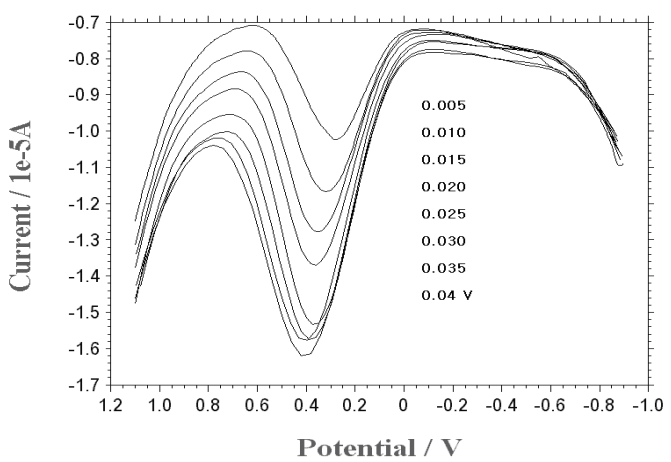

(b)

(c)

Fig. 2. (a) Various amplitudes of $0.10,0.15,0.20,0.25,0.30,0.35$ and $0.40 \mathrm{~V}$ for finding the optimal parameter using SW voltammograms, (b) SW voltammograms at diverse increment potential of $0.005,0.010,0.015,0.020,0.025,0.030$, 0.035 and $0.04 \mathrm{~V}$, and (c) SW voltammograms from accumulation times of 10, 20, 50, 100, 200, 300, 400 and $500 \mathrm{sec}$. Other parameters were also observed.

current was the second voltammogram of $0.010 \mathrm{~V}$ with $7.673 \times 10^{-6} \mathrm{~A}$. Therefore, the optimum increment potential was decided as $0.010 \mathrm{~V}$. The parameters used in this detection were the optimum $\mathrm{pH}$ and amplitude, the optimum frequency of $556 \mathrm{~Hz}$, and the same parameters as the former procedure. Optimum frequency was also obtained through the detection before determining the optimum increment. Fig. 2(c) was the result of examination of the SW accumulation time for fenitrothion with the same electrolyte solution and reagent. Accumulation time varied from 10 to $500 \mathrm{sec}$ with the strength of peak current of 2.023 to $23.130 \times 10^{-6} \mathrm{~A}$. The peak increased gradually until $400 \mathrm{sec}$, the seventh current, with the strongest strength, and then reduced at $500 \mathrm{sec}$, the last current, with $19.830 \times 10^{-6} \mathrm{~A}$. $400 \mathrm{sec}$ was also placed at $0.4 \mathrm{~V}$ completely like other peaks in the prior two examinations. Thus, $400 \mathrm{sec}$ was recognized as the optimum accumulation time for fenitrothion. Before this examination, the optimum initial potential for detection was set at $-0.9 \mathrm{~V}$. The parameters for this detection were optimum $\mathrm{pH}$ of 4.68, amplitude of $0.15 \mathrm{~V}$, frequency of $556 \mathrm{~Hz}$, increment of $0.01 \mathrm{~V}$ and initial potential of $-0.9 \mathrm{~V}$, and sensitivity of $1 \mathrm{e}-5 \mathrm{AV}^{-1}$. Under these conditions, analytical interference ion was examined. 


\subsection{Interference test}

The two kinds of interference ion are shown in Fig. 3(a) and Fig. 3(b). The results of interference from seven kinds of heavy metals are shown in Fig. 3(a). First, a peak current was measured in $0.1 \mathrm{M}$ ammonium phosphate electrolyte solution added with $1 \mathrm{ppm}$ fenitrothion. After that, other metals of 10 ppm were spiked into the electrolyte solution, and their interference peak current was calculated. $\mathrm{Ba}, \mathrm{Cr}$, $\mathrm{Ce}, \mathrm{Hg}, \mathrm{Ge}, \mathrm{Fe}$ and $\mathrm{Cd}$ affect fenitrothion as 413.04, $-94.60,9.59,98.68,-22.57,129.47$ and $616.25 \%$, respectively. At this condition, fenitrothion was expressed as number 1, and other numbers expressed heavy metals in that order for easy exhibition. $\mathrm{Cd}$, designated as 8 , interfered with $30.620 \times 10^{-7} \mathrm{~A}$ peak current. At that time, the optimum $\mathrm{pH}$ of 4.68 and $100 \mathrm{sec}$ was adopted. The result of interference from five pesticides is shown in Fig. 3(b) at $100 \mathrm{sec}$ and optimum $\mathrm{pH}$ of 4.68 . The fenitrothion of $10 \mathrm{ppm}$ and other analogous pesticides of $100 \mathrm{ppm}$ were utilized to observe the effects. The order of this examination is the same as the previous test. Chlorothalonil,

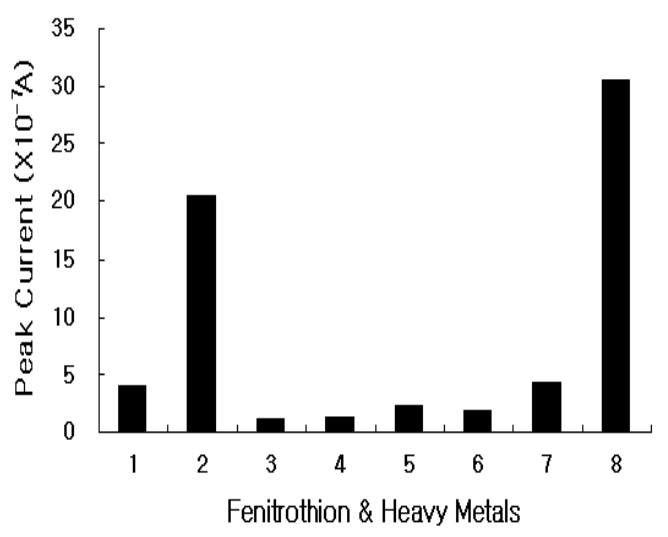

(a) dichlorvos, simazine, thiram, and diazinon interfered fenitrothion at $87.27,54.82,8.99,-86.09$ and $-9.81 \%$, respectively. Like the former examination, fenitrothion was shown as number 1, and other numbers indicated above pesticides in that order in Fig. 3(b). Out of them, number 4 pesticide, simazine, made the most effect on fenitrothion with $3.078 \times 10^{-7} \mathrm{~A}$. These interfering heavy metals and pesticides could be adjusted using standard addition methods.

\section{Linear Working Ranges, Statistics and Application}

At optimum conditions, the detection of fenitrothion in low concentration was made possible. This experiment was performed in $\mathrm{ppm}$, $\mathrm{ppb}$ and $\mathrm{ppt}$ ranges using a working electrode of Hg-CNTPE. All of SW voltammograms in ppm concentration appeared at around $0.4 \mathrm{~V}$, and were sharp and linear. A graph drawn by their peak currents was almost directly proportional. Spiked fenitrothion changed into $5,10,15,30,45,60,75,90$ and $105 \mathrm{ppm}$, and

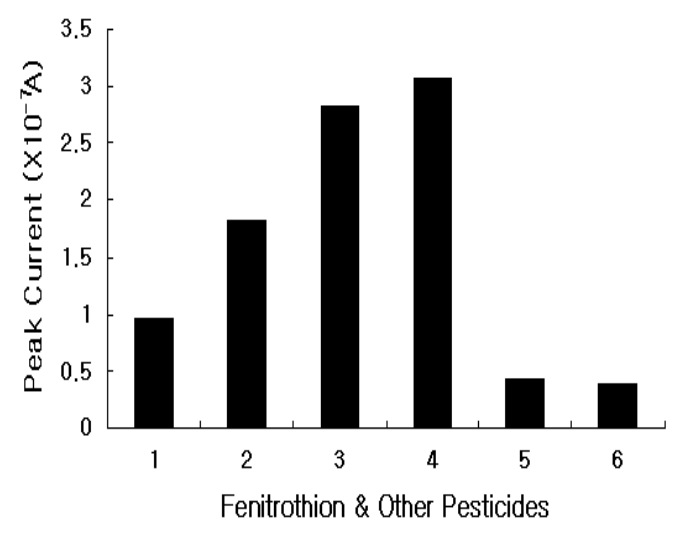

(b)

Fig. 3. (a) The interference effect on fenitrothion(1) from various heavy metals of $\mathrm{Ba}(2), \mathrm{Cr}(3), \mathrm{Ce}(4), \mathrm{Hg}(5), \mathrm{Ge}(6), \mathrm{Fe}(7)$ and $\mathrm{Cd}(8)$ ions in the ratio of $1 \mathrm{mgL}^{-1}$ fenitrothion : $10 \mathrm{mg} \mathrm{L}^{-1}$ other ions and (b) interference from analogous pesticides such as chlorothalonil(2), dichlorvos(3), simazine(4), thiram(5) and diazinon(6) in the ratio of $10 \mathrm{mgL}^{-1}$ fenitrothion(1) : $100 \mathrm{mgL}^{-1}$ other pesticides. With $\mathrm{pH}$ of 4.68 , amplitude of $0.15 \mathrm{~V}$, frequency of $556 \mathrm{~Hz}$, increment of $0.01 \mathrm{~V}$, initial potential of $-0.9 \mathrm{~V}$, other parameters were used for optimum conditions. 


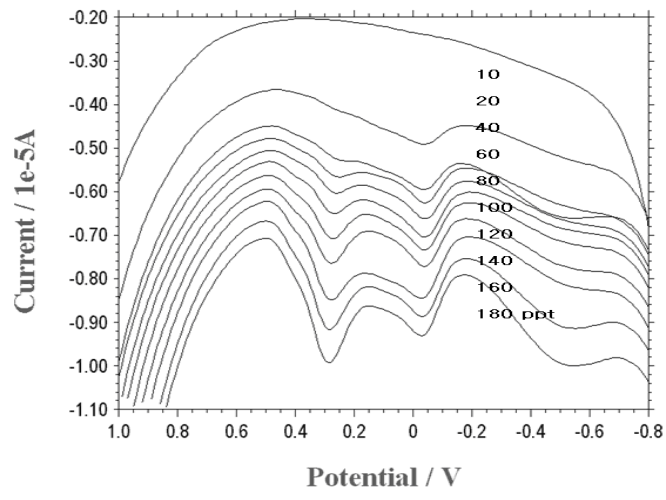

(a)

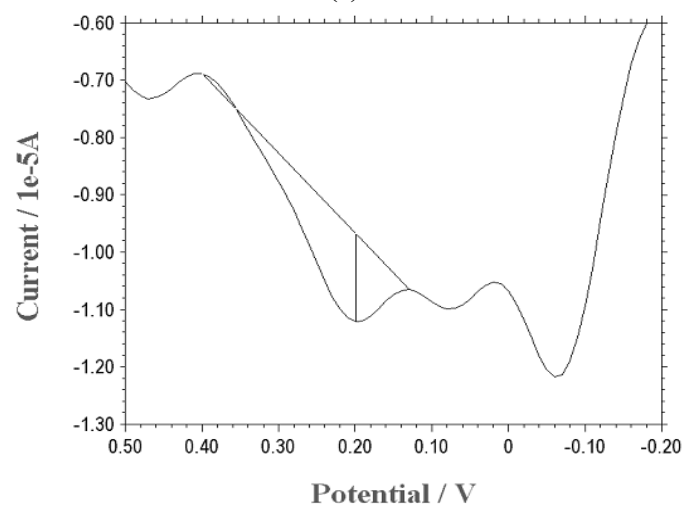

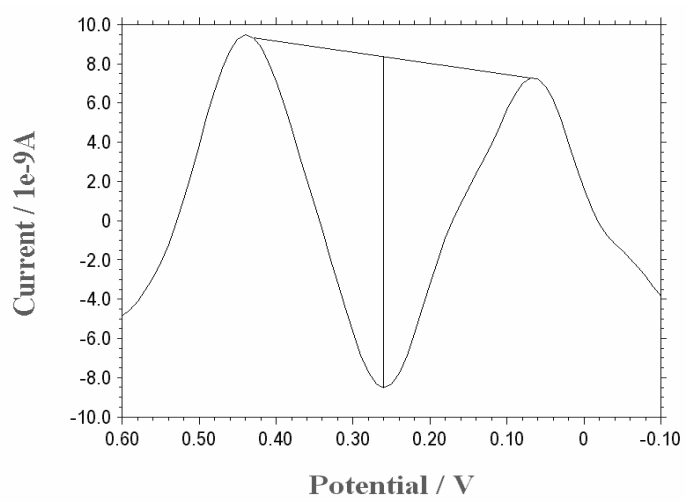

(b)

(c)

Fig. 4. (a) SW voltammograms of various fenitrothion concentration of 10, 20, 40, 60, 80, 100, 120, 140, 160 and 180 ppt using $0.1 \mathrm{M}$ ammonium phosphate solution as electrolyte at $\mathrm{pH}$ of 4.68 and $100 \mathrm{sec}$ accumulation time, (b) SW voltammogram from a live plant using $50 \mathrm{ppm}$ fenitrothion spike, and (c) detection in the brain of a live fish with 70 ppm spike in fish bowl water.

they yielded between 4.472 and $66.250 \times 10^{-6} \mathrm{~A}$ peak high with an optimum $\mathrm{pH}$ of 4.68, 0.1 M electrolyte solution of ammonium phosphate and $100 \mathrm{sec}$ accumulation times. Next, detection in the ppb unit was performed using SWASV. Its voltammograms were also dense and presented at the potential of 0.4 $\mathrm{V}$ as in the case of ppm. Various ppb concentrations were $10,20,30,40,50,70,90,110,130$ and 150 , and their peak current increased linearly with the same conditions as the previous detection. The infinitesimal concentration of ppt was conducted. The concentrations differed as 10, 20,40,60, 80, 100, $120,140,160$ and 180, and their peak current grew linearly from 2.014 to $19.280 \times 10^{-7} \mathrm{~A}$ high. The result of this examination in ppt concentration is indicated in Fig. 4(a). The peak current was shown clearly at $0.4 \mathrm{~V}$ like in the other concentrations. When a graph was drawn using the peak current, regression equation and correlation were deduced as $\mathrm{y}=$ 0.1095X-2.2089 (X: concentration, Y: peak current in A), $R^{2}=0.9766$, respectively. Conditions for this examination were the same with those of prior 
detections. Through these investigations, it is verified that the effect of Hg-CNTPE is good enough to measure fenitrothion in low concentration. Although there was no statistical finding, the calculation was repeated 5 times at the optimum $\mathrm{pH}$ of 4.68 and 0.1 $\mathrm{M}$ ammonium phosphate electrolyte solution. Before fenitrothion was measured, it was confirmed if there was any SW signal at blank condition 15 times. After verifying that there was no signal at all, $10 \mathrm{ppb}$ fenitrothion was searched 5 times and the results were overlaid. The clear peak currents were observed at $0.4 \mathrm{~V}$, and the peak current between 3.643 and $4.681 \times 10^{-7} \mathrm{~A}$ was obtained. Based on this study, the relative standard deviation (RSD) was determined as $0.097 \% \quad(n=5)$. Applying the standard addition method corrected the interference of other species in this examination. Under these conditions, the applications were conducted using a living plant and a brain of a living carp. The three electrodes (wire type, $\mathrm{Ag} / \mathrm{AgCl}$ electrode, $\mathrm{Pt}$ electrode and Hg-CNTPE) were inserted directly into carp's tissues using a macro diameter dental drill. Fenitrothion in these tissues were detected as shown in Fig. 4(b) and Fig. 4(c). A plant for this study was prepared by spiking $50 \mathrm{ppm}$ fenitrothion at once in the water where the plant had been grown. After setting it aside for about one day, the three electrodes were implanted into the plant tissue using a hand drill and detection was initiated. The consequence of this measurement is shown in Fig. 4(b). The peak current was also observed at the potential of $0.4 \mathrm{~V}$ at $0 \mathrm{sec}$ and optimum conditions. Thus, the presence of fenitrothion was confirmed. More specified conditions were examined. A live carp's brain was used for the last application. Using fresh fish, wire type working electrode was inserted into the head skeleton through a $3 \mathrm{~mm}$ diameter hole using a dental drill, and was interfaced to the electrochemical workstation. The wire type counter and reference electrodes were inserted into the brain tissue using the same method. These electrodes were connected to the workstation, and the open tissue was closed using a dental binder. On the first day, 20 ppm fenitrothion laced water was prepared, and the fish was placed in the water. The next day, the water was spiked further with $50 \mathrm{ppm}$ fenitrothion. After another day, the pesticide in the fish's brain was detected, and the results are shown in Fig. 4(c). There was a peak current at around $0.4 \mathrm{~V}$, and the existence of fenitrothion in the live fish's brain was monitored with no damage or destruction of any cell.

\section{Conclusions}

$\mathrm{Ag} / \mathrm{AgCl}$ reference electrode, platinum counter electrode and Hg-CNTPE working electrode were used to detect the pesticide fenitrothion $\left(\mathrm{C}_{9} \mathrm{H}_{12} \mathrm{NO}_{5} \mathrm{PS}\right.$. $\mathrm{MW}=277.24)$ using cyclic voltammetry (CV) and square wave anodic stripping voltammetry (SWASV).

Hg-CNTPE electrode was found to be better than other common type electrodes in detecting fenitrothion. This electrode could detect fenitrothion in even infinitesimal concentration of 'ppt', and directly detect its presence in a live plant's tissue and a live carp's brain. These applications were successfully carried out without damage or destruction of tissues. The precision was also as effective as RSD of $0.097 \%(\mathrm{n}=5)$ using $10 \mathrm{ppb}$ fenitrothion. Assaying fenitrothion using $\mathrm{CV}$ and SWASV remains rare until now even if this method is very simple and relatively cheaper than established methods. Thus, this study 
offers a valuable contribution to the field of monitoring fenitrothion.

\section{References}

Baroja, O., Unceta, N., Sampedro, M. C., Goicolea, M. A., Barrio, R. J., 2004, Optimization and validation of a method of analysis for fenitrothion and its main metabolites in forestry air samples using sorbent tubes with thermal desorption cold trap injection and gas chromatography-mass spectrometry, Journal of Chromatograph A., 1059, 165-170.

Bhushan, B., Samanta, S. K., Chauhan, A., Chakraborti, A. K., Jain, R. K., 2000, Chemotaxis and Biodegradation of 3-Methyl-4-Nitrophenol by Ralstonia sp. SJ98, Biochemical and Biophysical Research Communications., 275, 129-133.

Hernandez, F., Sancho, J. V., Pozo, O. J., 2004, An estimation of the exposure to organophosphorus pesticides through the simultaneous determination of their main metabolites in urine by liquid chromatography-tandem mass spectrometry, Journal of Chromatography B., 808, 229-239.

Khuder, S. A., Mutgi, A. B., Schaub, E. A., 1998, Meta-Analyses of Brain Cancer and Farming, American Journal of Industrial Medicine., 34, 252260.

Lambropoulou, D. A., Albanis, T. A., 2003, Headspace solid-phase microextraction in combination with gas chromatography-mass spectrometry for the rapid screening of organophosphorus insecticide residues in strawberries and cherries, Journal of Chromatography A., 993, 197-203.

Montesinos, T., Perez-Munguia, S., Valdez, F., Jean-Louis, M., 2001, Disposable cholinesterase biosensor for the detection of pesticides in water-miscible organic solvents, Analytica Chimica Acta., 431, 231-237.

Mulchandani, P., Chen, W., Mulchandani, A., Wang, J., Chen, L., 2001, Amperometric microbial biosensor for direct determination of organophosphate pesticides using recombinant microorganism with surface expressed organophosphorus hydrolase, Biosensors \& Bioelectronics., 16, 433-437.

Neufeld, T., Eshkenazi, I., Cohen, E., Rishpon, J., 2000, A micro flow injection electrochemical biosensor for organophosphorus pesticides, Biosensors \& Bioelectronics., 15, 323-329.

Ni, Y., Qiu, P., Kokot, S., 2006, Simultaneous determination of three organophosphorus pesticides by differential pulse stripping voltammetry and chemometrics, Analytica .,69,216-225.

Reybier, K., Zairi, S., Jaffrezic-Renault, N., Fahys, B., 2002, The use of polyethyleneimine for fabrication of potentiometric cholinesterase biosensors, Talanta., 56, 1015-1020.

Sanchez-Ortega, A., Sampedro, M. C., Unceta, N., Goicolea,M. A., Barrio, R. J., 2005, Solid-phase microextraction coupled with high performance liquid chromatography using on-line diode-array and electrochemical detection for the determination of fenitrothion and its main metabolites in environmental water samples, Journal of Chromatography A., 1094, 70-76.

SanLnchez, M. E., Estrada, I. B., Martinez, O., Martin-Villacorta, J., Aller, A., Moran, A., 2004, Influence of the application of sewage sludge on the degradation of pesticides in the soil, Chemosphere., 57, 673-679.

Schellin, M., Hauser, B., Popp, P., 2004, Determination of organophosphorus pesticides using membraneassisted solvent extraction combined with large volume injection-gas chromatography-mass spectrometric detection, Journal of Chromatography A., 1040, 251-258.

Schoning, M. J., Block, K. R., Musahmeh, K., Mulchandani, M., Wang, A. J., 2003, A dual amperometric/potentiometric FIA-based biosensor for the distinctive detection of organophosphorus pesticides, Sensors and Actuators B., 95, 291-296. 
Settimi, L., Masina, A., Anderion, A., Axelson, O., 2003, Prostate Cancer And Exposure To Pesticide In Agricultural Settings, International Journal. Cancer., 104, 458-461.

Shi, M., Xu, J., Zhang, S., Liu, B., Kong, J., 2006, A mediator-free screen-printed amperometric biosensor for screening of organophosphorus pesticides with flow-injection analysis (FIA) system, Talanta., 68, 1089-1095.

Solna, R., Sapelnikova, S., Skladal, P., Winther-Nielsen, M. C., Carlsson, C. J., Emneus, J., Ruzgas,T., 2005, Multienzyme electrochemical array sensor for determination of phenols and pesticides, Talanta., 65, 349-357.

Sotiropoulou, S., Chaniotakis, N. A., 2005, Lowering the detection limit of the acetylcholinesterase biosensor using a nanoporous carbon matrix, Analytica Chimica Acta., 530, 199-204.

Sudo, M., Kunimatsu, T., Okubo, T., 2002, Concentration and loading of pesticide residues in Lake Biwa basin (Japan), Water Research., 36, 345-329. Tsoukali, H., Theodoridis, G., Raikos, N., Grigoratou,
I., 2005, Solid phase microextraction gas chromatographic analysis of organophosphorus pesticides in biological samples, Journal of Chromatography B., 822, 194-200.

Vidal, J. C., Esteban, S., Gil, J., Castillo, J. R., 2006, A comparative study of immobilization methods of a tyrosinase enzyme on electrodes and their application to the detection of dichlorvos organophosphorus insecticide, Talanta., 68, 791-799.

Zambonin, C. G., Quinto, M., De Vietro, N., Palmisano, F., 2004, Solid-phase microextraction. gas chromatography mass spectrometry: A fast and simple screening method for the assessment of organophosphorus pesticides residues in wine and fruit juices, Food Chemistry., 86, 269-274.

Zuin, V. G., Yariwake, J. H., Bicchi, C., 2003, Fast supercritical fluid extraction and high-resolution gas chromatography with electron-capture and flame photometric detection for multiresidue screening of organochlorine and organophosphorus pesticides in Brazil's medicinal plants, Journal of Chromatography A., 985, 159-166. 